\title{
Evaluation of the sensory perception of sweet taste in people with Diabetes Mellitus type 2
}

\author{
Avaliação da percepção sensorial ao gosto doce em pessoas com Diabetes Mellitus tipo 2
}

Vanéria Ribeiro Dias ${ }^{1}$, Jamille Marinho Brazil ${ }^{1}$, Juliane Angelica Reges Almeida ${ }^{1}$, Camile de Souza Silva ${ }^{1}$, Maria Patrícia Milagres ${ }^{1}$

Objective: to evaluate the perception of patients with type 2 diabetes through the threshold index test for the sweet taste. Methods: a cross-sectional study with 80 adults of both genders, divided into two groups: control, composed of non-diabetics, and test, with diabetic patients. The evaluation of sensory perception held by the sensitivity test to determine the threshold index. The tests were conducted on five sections containing different concentrations of sucrose. Statistical analysis was held using the $t$ test, adopted $P<0.05$. Results: when comparing the average of the thresholds to detect sweet taste between diabetics and non-diabetics, it was known that diabetics are less sensitive to sweet stimuli. Conclusion: individuals with Diabetes Mellitus 2 have higher threshold index value for the sweet taste, which may contribute to the increase in sugar consumption.

Descriptors: Diabetes Mellitus, Type 2; Sensory Thresholds; Ageusia.

Objetivo: avaliar a percepção sensorial de pacientes com Diabetes Mellitus tipo 2, por meio do teste de índice limiar para o gosto doce. Métodos: estudo transversal, composto por 80 adultos de ambos os sexos, divididos em dois grupos: controle, composto por não diabéticos, e teste, formado por pacientes diabéticos. Avaliação da percepção sensorial realizada pelo teste de sensibilidade para determinação do índice limiar. Testes conduzidos em cinco sessões, contendo as concentrações diferentes de sacarose. Análise estatística por meio do teste t, adotado $\mathrm{p}<0,05$. Resultados: ao comparar a média dos limiares para detecção do gosto doce entre diabéticos e não diabéticos foi notório que os diabéticos são menos sensíveis ao estímulo doce. Conclusão: indivíduos com Diabetes Mellitus 2 apresentam valor de índice limiar maior para o gosto doce, o que pode contribuir para o aumento do consumo de açúcar.

Descritores: Diabetes Mellitus Tipo 2; Limiar Sensorial; Ageusia.

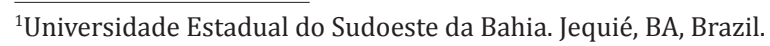

Corresponding author: Jamille Marinho Brazil

Rua José Moreira Sobrinho, s/n - Jequiezinho, CEP: 45206-190. Jequié, BA, Brazil. E-mail: jamille.marinho@hotmail.com 


\section{Introduction}

The taste plays an important role in the people's security and quality of life, as the loss or impairment of gustatory function creates an environment to domestic accidents, such as the risk of food poisoning by eating spoiled food ${ }^{(1)}$. Also, the taste influence on the food choices, allowing the individual to choose the food he likes most from the sensory characteristics provided by the substances contained in it ${ }^{(2)}$.

In this perspective, taste sensitivity impairment may lead to the need of the individual ingest greater quantities of substances for the perception of taste, contributing to increasing the sodium and sugar intake. The exacerbated consumption of these nutrients can contribute to the development or worse the diseases such as hypertension and diabetes mellitus type $2^{(3)}$.

Furthermore, studies that correlate the taste perception in food choice are key to understanding factors related to the anatomy and physiology of taste, and to hormonal modulation and genetic variation involved in this process. In this context, understanding factors related to taste perception, allows evaluating the feeding behavior of chronic patients ${ }^{(4)}$.

Thus, the perception of taste occurs in the taste buds, primary sensory cells responsible for taste. These cells can recognize the basic tastes: sweet, sour, salty, bitter and umami. The response caused by Sweet stimuli are associated with specific membrane receptors, mediated by messengers, adenosine 3',5'-cyclic monophosphate and inositol triphosphate ${ }^{(5)}$.

Sensory analysis is a widely used tool to evaluate the gustatory system because it allows the individual to understand, identify and/or distinguish qualitatively and/or quantitatively one or more stimuli received. Among the sensitivity of tests used, the electrogustometry and the whole mouth stimulation test can be highlighted ${ }^{(6)}$.

The electrogustometry is based on the weak electrical stimulation and reliable method for measuring taste in a high concentration. However, it has the limitation to evaluate the bitter taste ${ }^{(7)}$. In turn, the stimulation of mouth allows extensive contact with gustatory stimulation buttons present in the buds located on the surface of the tongue and the palate mucosa and, in smaller numbers, in throat $\operatorname{areas}^{(8)}$.

The threshold index method for the whole mouth stimulation technique has been used on a large scale. In this method, the basic taste thresholds detection are determined on the sessions, in which three samples are provided to the participant (two are water, and one is the solution containing the taste), being asked to identify the different, passing the sample through the mouth. In each session, the stimulus concentration is increased. Thus, the session is determined when the individual began to detect the stimulus. Thus, the threshold detection is the minimum concentration of a substance that the evaluator can identify a different feel pattern ${ }^{(9)}$.

In this context, researchers have used the threshold index test for studies on eating habits, attitudes, and diseases related to taste sensitivity for a given substance ${ }^{(10-11)}$. A study conducted to determine the threshold detection in cancer patients treated with chemotherapy concluded that they have lower threshold detection rates than the control group $^{(10)}$. Research using the threshold index test in hospitalized patients found that the mortality rate is higher in people less sensitive to tastes ${ }^{(12)}$. Another study of alcoholics found that alcohol consumption may decrease the salty and sweet taste sensitivity ${ }^{(13)}$.

Thus, it is noted that some diseases and lifestyle contribute to the development of disorders in taste, such as Diabetes Mellitus type 2, liver diseases, tumors and alcohol use. Furthermore, the use of drugs, head trauma, upper respiratory tract infections and exposure to toxic substances significantly influence to the taste loss ${ }^{(5,11)}$. 
In patients with diabetes, the increase in glucose levels can produce an inadequate response to the perception of sweet taste, and bring micro and macrovascular complications ${ }^{(14)}$. Thus, lifestyle change is important to maintain adequate levels of plasma glucose, such as the consumption of healthy food, loss and/or weight control and physical activity ${ }^{(15)}$.

The food choice is influenced by several factors, highlighting the sensory characteristics of the food such as taste. The altered taste sensitivity may interfere with the perception of sweet taste, contributing to the increase in sugar intake. The exposure to high amounts of this nutrient contributes to the development and worsening of diabetes. Therefore, it is emphasized the importance of studying the taste sensitivity in patients with Diabetes Mellitus type 2 , since studies show that there is a reduction in salivary flow in diabetic patients ${ }^{(15-16)}$ interfering with the taste sensitivity. However, there are few studies involving these individuals and the threshold index detection for a sweet taste.

Highlighting that control sugar consumption is essential for the treatment, control, and prevention of comorbidities in diabetic patients, and that changes in the threshold index can change this control, the aim of this study was to evaluate the perception of patients with Diabetes mellitus type 2 by the threshold index test for sweet taste.

\section{Methods}

It is a cross-sectional study with a convenience sample, consisted of 80 volunteers of both genders, aged 20 to 59 years old, divided into two groups: control and test.

The control group had 40 non-diabetic individuals, students, teachers and employees of a State University, who were invited to participate in the research. The test group had 40 patients diagnosed with Diabetes Mellitus Type 2, patients of two health centers. The number of participants is by the provisions of the Brazilian Association of Technical and Standards ${ }^{(17)}$.

People with a dental prosthesis and or complications in the oral cavity, people who had drunk alcohol in the last 24 hours, smokers, elderly people, and individuals with a cold or flu, or with something that could influence the perception of taste were excluded. Data collection was conducted from August to November 2014 in the city of Jequié, Bahia, Brazil.

The sensitivity test was performed to evaluate the perception of the participants, determining the threshold index detection to sweet taste. For this, the methodology described in the Brazilian Standard ${ }^{(17)}$ and International Organization for Standardization was used ${ }^{(18)}$.

The quick method of determining threshold index test was used, where each evaluator conducted a series of five sensory tests of type 3-Alternative Forced Choice for a sweet taste. The samples were submitted to continuous and triangular way, in a monodic form, following increasing intensity of sucrose concentration, the concentrations being used in $0.5 ; 1.0 ; 2.0 ; 4.0$ and 8.0 grams of sucrose to one liter of water.

In each type 3-Alternative Forced Choice, the evaluator received three coded samples with threedigit random numbers, being two control samples (only mineral water) and one test sample (sucrose at a certain concentration).

The evaluators were asked to identify the sample who thought different, through an evaluation form. They were instructed to taste the samples from left to right, and then write the code sample in the form and circle the sample code that thought different.

Evaluators were located in individual cabins and instructed to rinse the mouth between each session to clean the taste buds. Moreover, a disposable cup for disposal of the solutions was available if they do not ingest the samples. 
The samples were given at room temperature in disposable cups with a capacity of $50 \mathrm{ml}$. The taste sensitivity test was performed in five sessions, containing the concentrations of sucrose in 0.5; 1.0; $2.0 ; 4.0$ and 8.0 grams (g)/liters (L), prepared according to the geometric series, recommended by the International Organization for Standardization ${ }^{(17)}$.

The standard samples in the concentrations above were prepared at the State University of Food Technology Laboratory of Southwest Bahia, using mineral water and sucrose as a solute, measured by analytical scale SHIMADZU AUW220D and then the samples were stored in containers at room temperature.

The tests results analysis was carried out from each participant threshold. The data were tabulated, following the application of Equation 1 to determine the individual threshold for each evaluator.

Equation 1 determining theindividual threshold considered that $\mathrm{C}_{0}$ is the highest concentration detected/recognized by the evaluator $\mathrm{i}$ and $\mathrm{C}_{+}$is the lowest concentration detected/recognized by a particular evaluator i, then for this evaluator, the individual threshold is given by equation 2 .

After determining the individual thresholds for each participant, Equation 3 was applied for obtaining the two groups threshold calculating the geometric mean of the $L_{i}$ values. Thus, for a group of 40 evaluators, the threshold index is given by equation 4 .

For the statistical analysis, the Statistical Package for the Social Sciences, version 21.0 was performed. The t-test $(\mathrm{p}<0.05)$ was used to compare the threshold for the sweet taste of the control group and the sweet test of the tasting group.

The study complied with the formal requirements contained in the national and international regulatory standards of research involving human beings.

\section{Results}

The study population ranged between 20 and 59 years old, $70.0 \%$ of the control group participants $(\mathrm{n}=28)$ were female, and the other $30.0 \%$ were male $(n=12)$. In the test group, there were $67.5 \%$ women $(n=27)$ and $32.5 \%$ were male $(n=13)$.

According to the results of the in threshold index test, sessions $1(0.5 \mathrm{~g} / \mathrm{L}), 2(1.0 \mathrm{~g} / \mathrm{L})$ and $3(2.0 \mathrm{~g} / \mathrm{L})$, respectively can be seen that only $3.0 \%(n=1), 13.0 \%$ $(n=5)$, and $40.0 \%(n=16)$ of the test group detected sweet taste stimuli. However, 20.0\% (n=8) 35.0\% $(n=14)$ and $63.0 \%(n=25)$ of the control participants $(n=8)$ detected the stimulus in the corresponding sessions.

In sections $4(4.0 \mathrm{~g} / \mathrm{L})$ and $5(8.0 \mathrm{~g} / \mathrm{L})$, it was noted the increase in the number of the control group individuals who identified sweet taste stimuli, being $68.0 \%(\mathrm{n}=27)$ in section 4 and $90.0 \%(\mathrm{n}=36)$ in section 5 . When comparing the results obtained in the test group and the control group in these sessions, there was a difference between groups to detect the sweet taste, since, in the sessions 4 and 5, 100.0\% ( $n=40)$ of the control group identified the stimulus.

Through the rapid method, the values found in the sessions allow to observe that the taste sensitivity to the sweet taste of nondiabetic is smaller in solute detected in a growing number of solutions presented than in the diabetic people.

When performing the calculation using the individual thresholds by the geometric mean of the highest concentration not detected and the lower concentration detected in diabetics and non-diabetics, it is possible to identify the average detection thresholds for sweet taste, being 1,35g/L for the test group and $2.48 \mathrm{~g} / \mathrm{L}$ for the control group.

When comparing the average of the thresholds to detect sweet taste among non-diabetic patients and 
in those with type 2 diabetes, there was a statistically significant difference $(\mathrm{p}<0.05)$. Thus, the diabetic group is less sensitive to sweet stimuli, with higher threshold index value.

\section{Discussion}

In this study, it was observed that the average thresholds to detect sweet taste were higher for diabetic patients $(\mathrm{p}<0.05)$. Thus, the results showed a decrease or loss of sensitivity to sweet taste for diabetic patients with the threshold index, compared to the control group.

The reduction and or loss of sensitivity to sweet taste can contribute to an increase in the intake of refined carbohydrates because this dysfunction may lead to higher consumption of sugar ${ }^{(19)}$. This fact is a risk factor for diabetics because the higher intake of sugar, the greater the increase in blood glucose.

The loss of taste perception in individuals with type 2 Diabetes Mellitus is related to hyposalivation, xerostomia and low production of taste protein. Furthermore, the deficiency or absence of taste interferes in salivation and maturation of the taste buds, causing changes in the perception of taste ${ }^{(3)}$. One of the limitations of the study was the use of only a primary taste, instead of the five tastes.

The mouth threshold index evaluation technique was efficient to evaluate the taste sensitivity in diabetic patients since the results of this study show that the average threshold to detect the sweet taste in non-diabetic individuals is lower when compared to diabetic individuals. These results corroborated with another study with a control group, pre-diabetic and diabetic patients, where it was observed that the average thresholds to detect sweet taste were different between the groups. The control group had a lower mean than the pre-diabetic and finally the diabetic individual ${ }^{(19)}$.

The loss of taste sensitivity may hinder to control sugar intake in the patient since he may think that he is consuming food with low sugar by feeling a little sweetness, but in fact, this feeling is related to the low sensitivity of the patient. This reported situation may even hinder the work of health professionals in the assessment and treatment of patients. Thus, it is suggested the use of gustatory sensitivity testing by health professionals as a way to evaluate the clinical and laboratory status of the affected patient of Diabetes Mellitus Type 2.

By being a disease that, at times, is asymptomatic, the clinical and laboratory evaluation is relevant to identify the actual pathological condition of the patient to contribute to a more suitable treatment. Thus, evaluation of taste sensitivity may be a new tool for the control of the clinical status of patients with Diabetes Mellitus type 2.

Identifying the loss of taste sensitivity in patients with type 2 Diabetes, the development of studies are necessary to minimize or eliminate this clinical condition. In this sense, physiology studies of taste tissues are highlighted, such as receptors. The T1R2/T1R3 receptor is responsible for the sweet taste perception, being the regulator of several metabolic processes, such as macronutrients ingested in the diet. This fact contributes to the treatment and maintenance of metabolic disorders such as diabetes $^{(20)}$.

\section{Conclusion}

The threshold index to detect the sweet taste is higher in people with Diabetes Mellitus type 2 compared with non-diabetic individuals. Therefore, diabetic patients have lower sensitivity to sweet taste, requiring higher sucrose concentrations to identify the sweetness of food and beverages.

Therefore, the loss of sensitivity to sweet taste in diabetics may contribute to intake food with high sugar concentration, being a risk factor for the worsening of the disease. However, it is necessary to develop new studies on the subject to intervening in improving sensitivity to sweet taste and consequently favor choices and healthier eating habits. 


\section{Acknowledgment}

To the Health Centre Júlia Magalhães and Jequié Health Center.

\section{Collaborations}

Dias VR, Brazil JM, Almeida JAR, Silva CS and Milagres MP participated in the conception and project or analysis and interpretation of data, article writing, relevant critical review of the intellectual content and final approval of the version to be published.

\section{References}

1. Boesveldt S, Lindau ST, McClintock MK, Hummel T, Lundström JN. Gustatory and olfactory dysfunction in older adults: a national probability study. Rhinology. 2011; 49(3):324-30.

2. Palheta NFX, Targino MN, Peixoto VS, Alcântara FB, Jesus CC, Araújo DC, et al. Anormalidades sensoriais: olfato e paladar. Arq Int Otorrinolaringol. 2011; 15(3):350-8.

3. Negrato CA, Tarzia O. Buccal alterations in diabetes mellitus. Diabetol Metab Syndr [Internet]. 2010 [cited 2016 Mar 13]; 15;2:3. Available from:http://dmsjournal.biomedcentral.com/ articles/10.1186/1758-5996-2-3

4. Loper HB, Sala ML, Dotson C, Steinle N. Taste perception, associated hormonal modulation, and nutrient intake. Nutr Rev. 2015; 73(2):83-91.

5. Hummel T, Landis BN, Hüttenbrink KB. Smell and taste disorders. GMS Curr Top Otorhinolaryngol Head Neck Surg [Internet]. 2011 [cited 2016 Mar 13]; 10: Available from: http://www.ncbi.nlm.nih. gov/pmc/articles/PMC3341581/

6. Piovesana PM, Gallani MCBJ, Sampaio KL. Revisão: metodologias para análise da sensibilidade gustativa ao sal. Braz J Food Technol. 2012; 15(3):18290.
7. Berling K, Knutsson J, Rosenblad A, Unge M. Evaluation of electrogustometry and the filter paper disc method for taste assessment. Acta OtoLaryngol. 2011; 131(5):488-93.

8. Meilgaard M, Civille G, Carr BT. Sensory evaluation techniques. Boca Raton: CRC Press; 2006.

9. Negri R, Di Feola M, Di Domenico S, Scala MG, Artesi G, Valente S, et al. Taste perception and food choices. J Pediatr Gastroenterol Nutr. 2012; 54(5):624-9.

10. Sánchez-Lara K, Sosa-Sánchez R, Green-Renner D, Rodríguez C, Laviano A, Motola-Kuba D, et al. Influence of taste disorders on dietary behaviors in cancer patients under chemotherapy. Nutr J [Internet]. 2010 [cited 2016 Mar 13]; 24(9):15. Available from: http://nutritionj.biomedcentral. com/articles/10.1186/1475-2891-9-15

11. Lampuré A, Schlich P, Deglaire A, Castetbon K, Péneau S, Hercberg $S$, et al. Sociodemographic, psychological, and lifestyle characteristics are associated with a liking for salty and sweet tastes in french adults. J Nutr. 2015; 145(3):587-94.

12. Solemdal K, Møinichen-Berstad C, Mowe M, Hummel T, Sandvik L. Impaired taste and increased mortality in acutely hospitalized older people. Chem Senses. 2014; 39(3):263-9.

13. Silva CS, Dias VR, Almeida JA, Brazil JM, Santos RA, Milagres MP. Effect of heavy consumption of alcoholic beverages on the perception of sweet and salty taste. Alcohol Alcohol. 2016; 51(3):3026.

14. Kota SK, Meher LK, Jammula S, Kota, SK, Modi KD. Genetics of type 2 diabetes mellitus and other specific types of diabetes; its role in treatment modalities. Diabetes Metab Syndr. 2012; 6(1):548.

15. Al-Maskari AY, Al-Maskari MY, Al-Sudairy S. Oral manifestations and complications of diabetes mellitus. Sultan Qaboos Univ. Med J. 2011; 11(2):179-86. 
16. Sousa MGM, Costa ALL, Roncalli AG. Estudo clínico das manifestações orais e fatores relacionados em pacientes diabéticos tipo 2 . Braz J Otorhinolaryngol. 2011; 77(2):145-52.

17. Associação Brasileira de Normas Técnicas. Norma Brasileira no 13172: Teste de sensibilidade em análise sensorial. Rio de Janeiro: ABNT; 1994.

18. International Organization for Standartization. Sensory analysis. Methodology. General guidance for measuring odour, flavour and taste detection thresholds by a three-alternative forced-choice (3-AFC) procedure. In: ISO International Standard. № 13301/International Organization for Standardization, Geneva: International Organization for Standartization; 2002. p. 27.
19. Wasalathanthri S, Hettiarachchi P, Prathapan S . Sweet taste sensitivity in pre-diabetics, diabetics and normoglycemic controls: a comparative cross sectional study. BMC Endocr Disord [Internet]. 2014 [cited 2016 Mar 13]; 14: 67. Available from: http://bmcendocrdisord.biomedcentral.com/ articles/10.1186/1472-6823-14-67

20. Laffitte A, Neiers F, Briand L. Functional roles of the sweet taste receptor in oral and extraoral tissues. Curr Opin Clin Nutr Metab Care. 2014; 17(4):379-85. 